\title{
FROM LAYOUT TO PHOTOPLAN: REFLECTIONS ON THE "rePRESENTATION" OF URBAN PLANNING
}

\author{
Jordi GOMIS ${ }^{1}$, Carlos TURÓN ${ }^{1}$
}

DOI: 10.21163/GT_2017.121.06

\begin{abstract}
:
When drawing a new urban plan, architects and town planners try, with sufficient skill, to represent what exists and what the new designed reality will be like. They are forced to disregard what they feel to be important in the representation and specify what is and what is not meaningful in the designed planning and how it will be shown on the drawing. If a plan specifies this capacity for abstraction and synthesis of the urban planning task it is without a doubt the floor plan drawing. This drawing simultaneously materializes the act of designing the city and an exercise in communication and graphic language that explains, and at the same time expresses, what has been designed. To manage to produce images capable of clearly communicating the results of the urban design process thus becomes a fundamental task of the planner.
\end{abstract}

Key-words: Planning, Graphic representation, Technical drawing, City Planning.

\section{INTRODUCTION}

One of the plans that goes beyond simple urban planning is the layout, and not precisely due to any special technical demands. Layouts are drawings in which the developer seeks to present the final result of the design process of his arrangement. It could perhaps be considered one of the "least" technical of all the plans that may make up a planning document, but, at the same time, it is often the most significant. This cartographic visual expression is an image composed of signs, symbols and codes that provide their interpretation. The architects are using a specific language as well, in order to communicate and also create and develop their projects, to follow their ideas (Vartic, 2015).

The layout is not a conventional floor plan, as can be understood from a purely architectural or urbanistic view. It is a plan containing graphic resources that are often of reduced technical precision but, nevertheless, they increase the readability and understanding what is drawn. It is, therefore, a plan that the technician carries out with the clear intention that the graphic message should be special and essentially effective, clearly communicating and displaying the ideas contributed by the urban planner in the foreseen planning. In some cases this type of plan could be confused with the presentation plans that some architects draw to show the proposed arrangement. By this we refer to conceptual plans that present a representation that reduces the "foreseen outcome" to simple but striking images, and where the theoretical intention of what has been planned is shown more abstractly and synthetically. That is to say a plan by specialists for specialists.

This is not the case in hand. In layouts, contrary to presentation plans like the one by Norman Foster for Friedrichstrasse in Berlin (Fig. 1), the technician does not always have to

\footnotetext{
${ }^{1}$ Universitat Rovira i Virgili, Department of Mechanical Engineering, 43007 Tarragona, Spain, jordi.gomis@urv.cat; carlos.turon@urv.cat.
} 
consider that the observer will be a person skilled in the field, but, regardless of whether the reader of the plan is a specialist or not, the urban planner prepares a graphic document that can be understood easily and immediately and that clearly expresses the structure and organization of the foreseen planning. The layout, as it is understood today, is a resource that urban planners started to apply commonly in the early twentieth century (Gravagnuolo, 1998), which became popular among architects and engineers during international urban planning congresses of the first half of the twentieth century. Thus, the technicians found in this graphic mechanism an ideal tool to effectively show the new theories concerning the future urban developments they proposed.

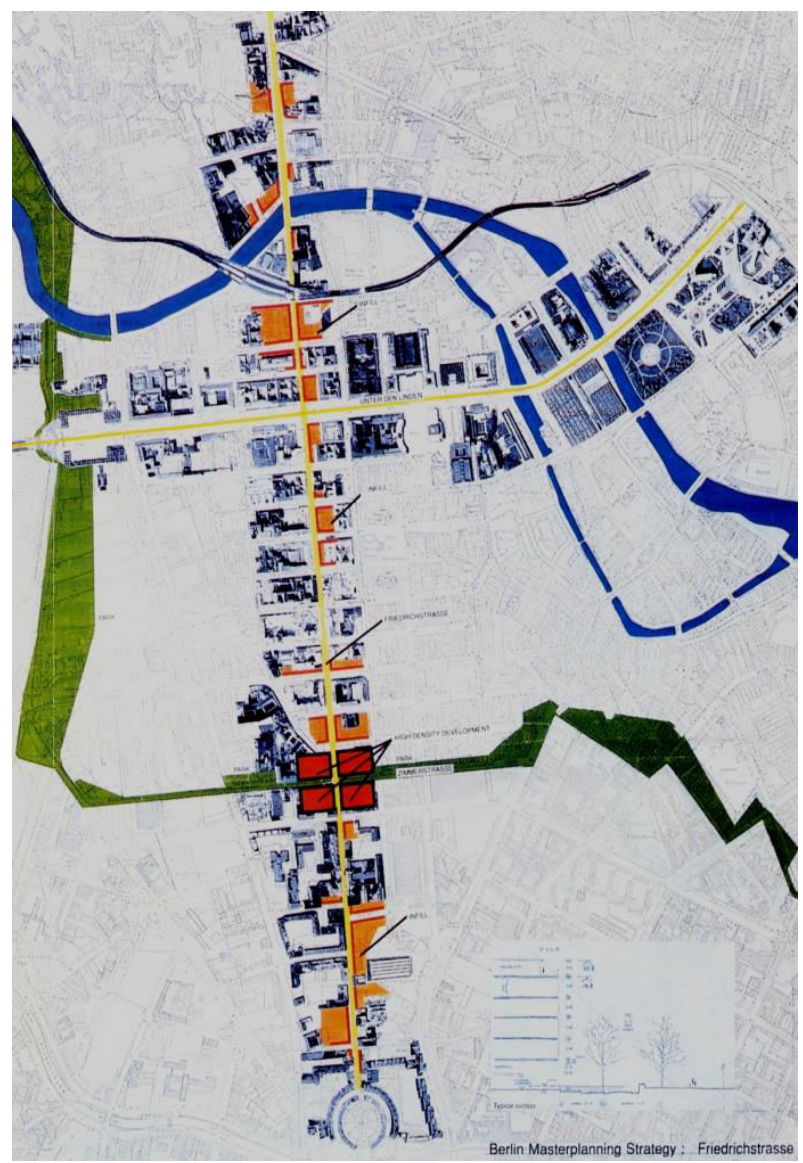

Fig. 1 Study for the development of Friedrichstrasse in Berlin. Norman Foster - 1990-.

(Source: Magnago, 1990)

\section{THE LAYOUT OR MASTER PLAN}

In the English-speaking world the "Layout" or "Master Plan" can include anything from a small area to a large portion of territory which is to be the subject of urban planning. Obviously, depending on the chosen scale of the drawing and the surface to be represented, 
the graphic mechanisms and resources used may vary greatly. From the use of freehand and black and white to the use of colour drawing or work with photoplans (Fig. 2).

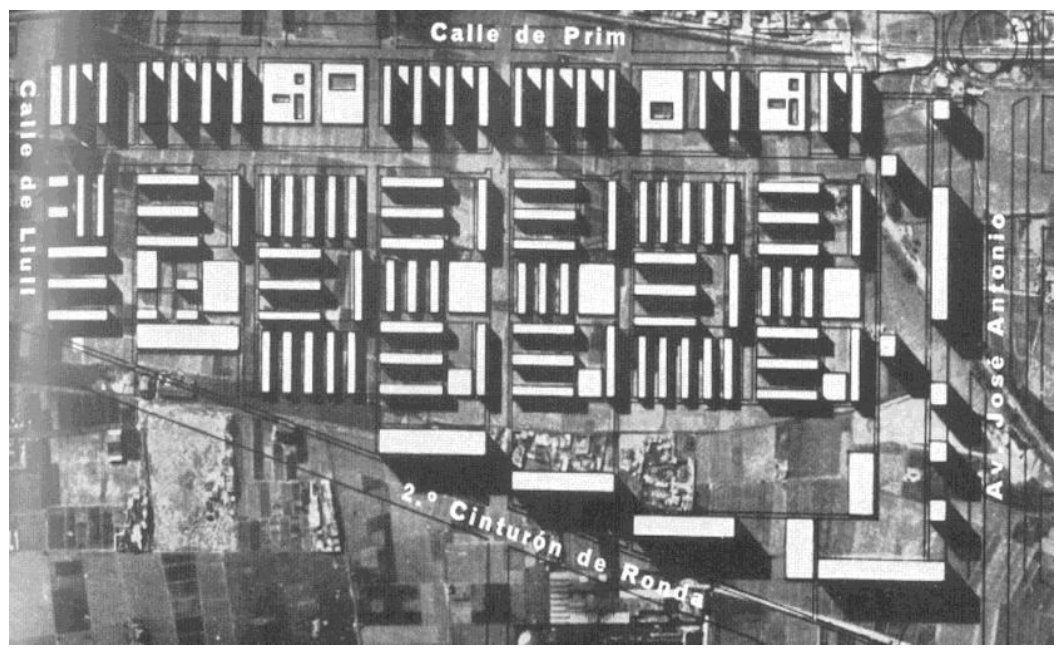

Fig. 2 Layout of the Partial Plan of south-west Besós. P. López Iñigo, E. Giralt, G. Giráldez, J. Puig Torné \& X. Subias -Architects- 1959. (Source: Pla, 1994)

The layout is the presentation plan par excellence. It is a plan to present the project in its most common and usual sense, one that shows the observer the new arrangement in a comprehensive manner. However, the use of this type of plan has certain limitations as it is often restricted to a relatively limited field of planning. That is to say, and in order to provide some kind of benchmark, they may be effective as of a similar area of intervention to that of a "partial plan" or lower (Fig. 3).

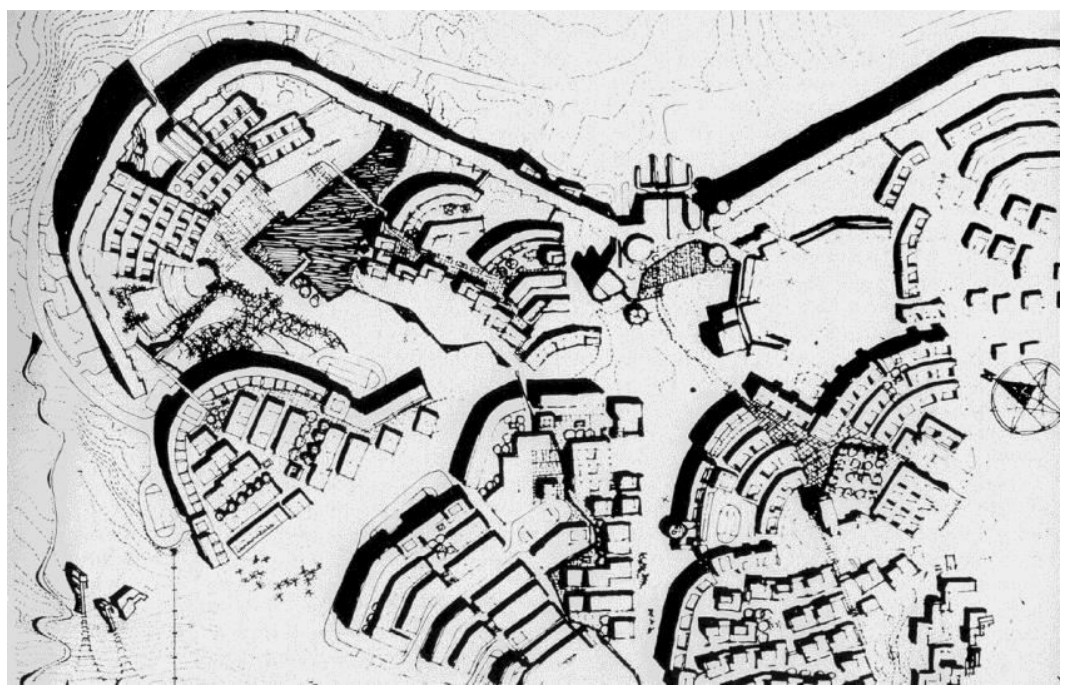

Fig. 3 "Master Plan" of the urbanization and buildings of Svappavaara, Lapland -Sweden-. Project by Ralph Erskine -Architect- 1963/1964. (Collymore, 1983) 
However, it should be clear that in referring to such a vague extension as could be interpreted from the "partial plan" benchmark size, this dimension should, however, be considered as something extremely indeterminate. Now, the reader will understand that we are dealing with a clearly ineffective plan, for example, in comparison with the preparation and representation of a general plan, where the managed land usually is excessively large, and where applying the specific characteristics of layouts neither makes any special sense nor, of course, has an optimal result.

These are precisely the characteristics that identify and determine the qualities of such drawings. They are plans that the technicians draw when the urban plan is of a size that allows the developer to present the planning, as a whole, almost like an architectural object, and thus display it. They are drawings that are more characteristic of architectural drawing and move away from the criteria for the application of graphic resources commonly used in delineating planning plans. They are often plans stuffed with graphic resources of all types (Fig. 4). They are usually drawings in which the technicians incorporate a range of graphic possibilities that go beyond the required accuracy of purely urbanistic drawing, which is generally rather concerned with the correct representation of the boundary or the precise definition and categorization of the zoning or the scope of intervention.

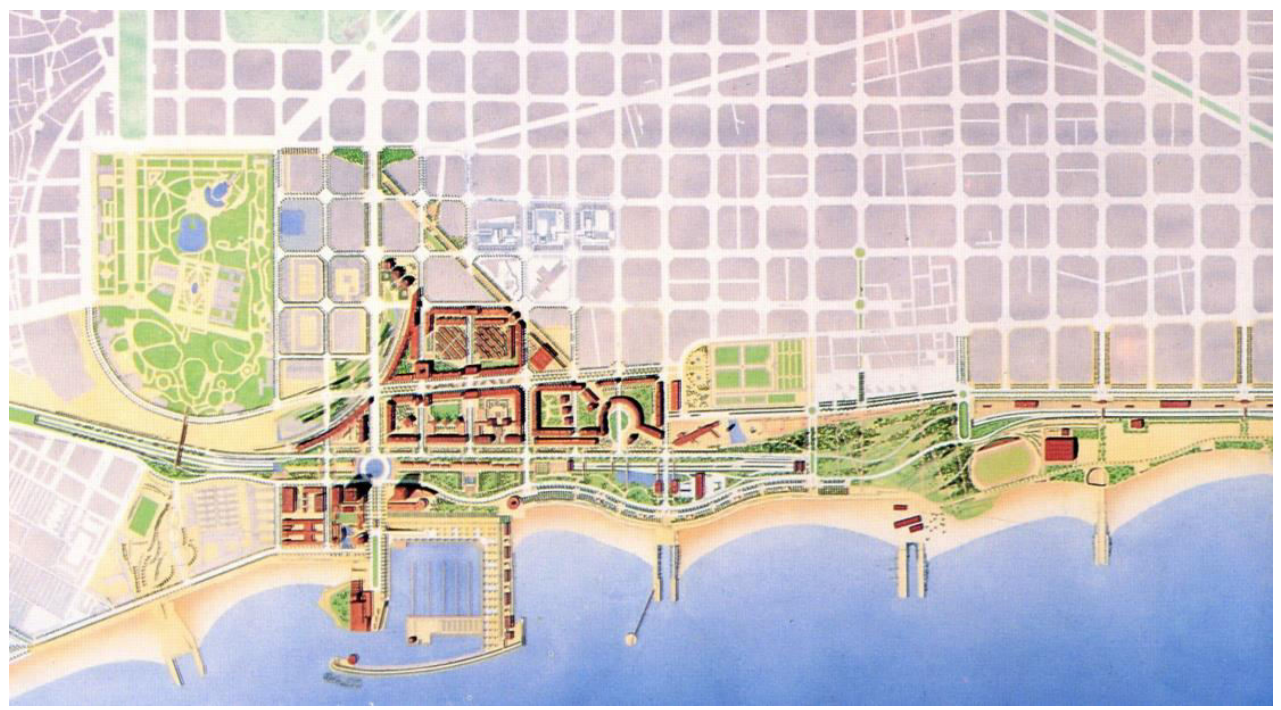

Fig. 4. General plan of the new Barcelona waterfront - Olympic Village 1992.

(Martorell J. M.et al. 1992)

So, these circumstances do not converge in an area of planning whose aim is the management of a certain size of territory or a municipality. Now, the question can immediately arise as to what is the maximum surface, in terms of size, on which a technician can express himself with some clarity and effectiveness through a layout. This is not always an easy question to answer and, in most cases, it depends on several variables. Even so, it seems clear that two of the main ones are as classic as they are predictable: what is the plan intended to communicate and what is the ability of the draughtsman to achieve it? 


\section{THE DRAWING OF THE CITY: THE REPRESENTATION OF THE "ARCHITECTURAL OBJECT"}

As explained, this type of drawing appears at the beginning of the 20th century, even though it is particularly difficult to find layouts dating from prior to the first half of the 20th century. Thus a sudden conceptual leap can be seen in the representation of urban planning, similar to the one caused by the drawings of Leonardo da Vinci and Giambattista Nolli when they established the floor plan as the fundamental plan in the representation of the city. In fact, Nolli introduced a representation of plant materials and crops on his map. Nolli list various type of land use and depicted each of them a specific symbology on the map (Baiocchi et al., 2013) using figurative drawings.

So, as of the second half of the 20th century the layout became "popularized". Conceptually and graphically produced from another representational perspective, these plans would try to show planning not according to its arrangement, sectorization and categorization, but from that of the presentation of a conceived architectural object. There is scarce use of colour in drawings from this period. It should be remembered that this was a period in which the blueprint was the dominant reproduction system and, therefore, from the beginning the urbanist had to prepare a compatible graphic solution. Only truly exceptional or unique works benefit from the addition of colour. Such special works that can or have to withstand the setback of their difficult and expensive copying and reproduction. Perhaps to offset this lack of colour the technicians decided to explore shadowing, freehand drawing, mechanisms of representation in perspective, the combination of purely linear drawing with organic strokes, or, for example, the use of the axonometry (Fig. 5).

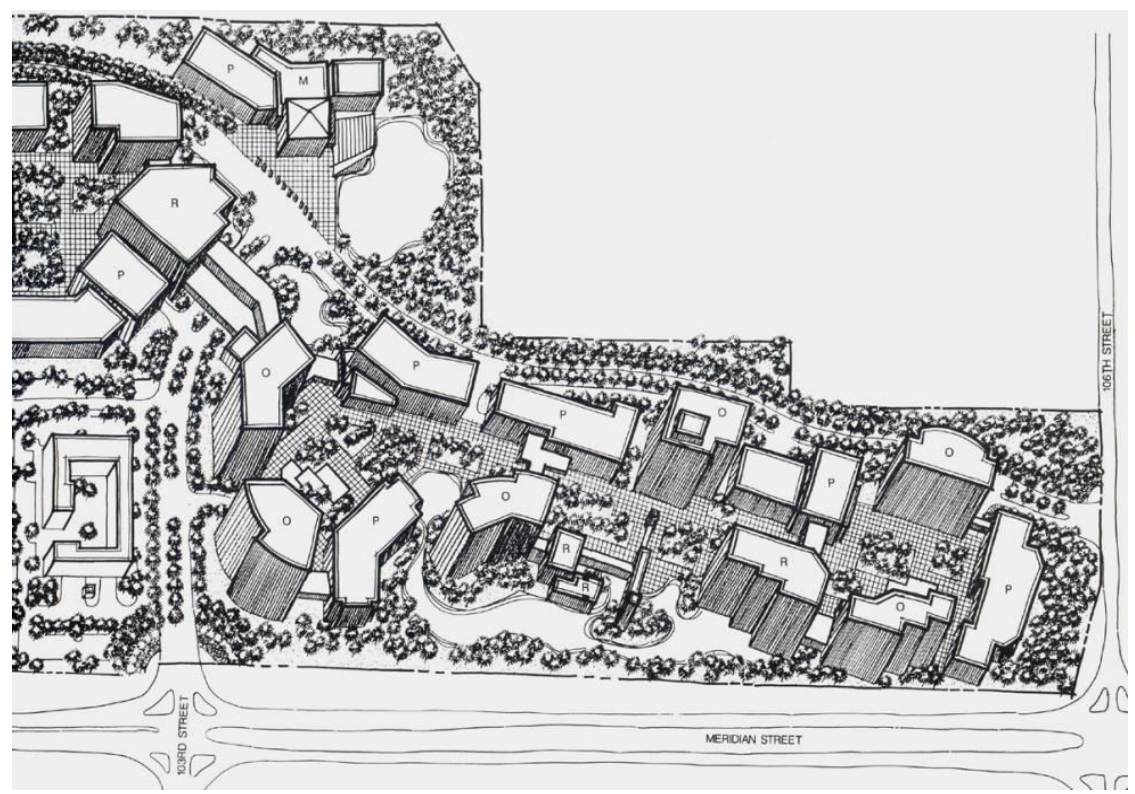

Fig. 5 "Master plan" drawing of the Illinois Street and Meridian Street, Indianapolis (Indiana, USA) using oblique axonometry as a graphic resource. Browning Day Mullins Dierdorf Inc. -Architects-, 1980. (Source: Walker \& Davis, 1990) 
However, it was in the 1990s and already during the 21 st century that layouts began to include colour permanently. The main feature is, therefore, the use of chromaticism in the planning area, leaving the surrounding area in black and white or using shades of grey. The use of shadowing and the rendering of trees and green areas also appear as noteworthy features. The latter is one of many common resources represented, but it can be seen how on layouts a compendium now appears of drawing mechanisms that are used at the same time, far more typical of architectural than of merely urbanistic drawing. That is to say, the technicians use a wide variety of graphic resources that are useful for them to draw plans that represent the proposed arrangement. They could be said to be "project presentation" plans, easily understandable by the whole of society; the urban planner thus referring to other graphic documentation for the strictly disciplinary representation of the planned arrangement. A variant of floor plan rendering has become established with the use, as base drawings, of photoplans. This gives a very clear picture of the land and, at the same time, of how planning is superimposed on it. The advantage of this type of plan is that it shows the viewer very clearly the implementation of what has been planned and how it will be organized on a real image of the territory.

Obviously, for the "layperson" it is an especially useful resource since it allows visually identifying the region for the future arrangement and, at the same time, enables getting a clear idea, a bird's eye view, of the final outcome of the foreseen planning. However, we should specify that the graphical accuracy of photoplans cannot be considered particularly rigorous, clearly becoming a "presentation" plan rather than a proper, scrupulous drawing rendering the planning. Its optimal visual results allow the reader of the document to immediately locate and understand the arrangement only matched by perspectives or scale models. Such perspectives and scale models in general involve a much higher cost. Lacking, for the time being, an essentially more technical and more precise style, they tend to contribute, through basically symbolic and figurative renderings, easily understandable images that are especially suitable and appropriate for "lay" observers (Fig.6).

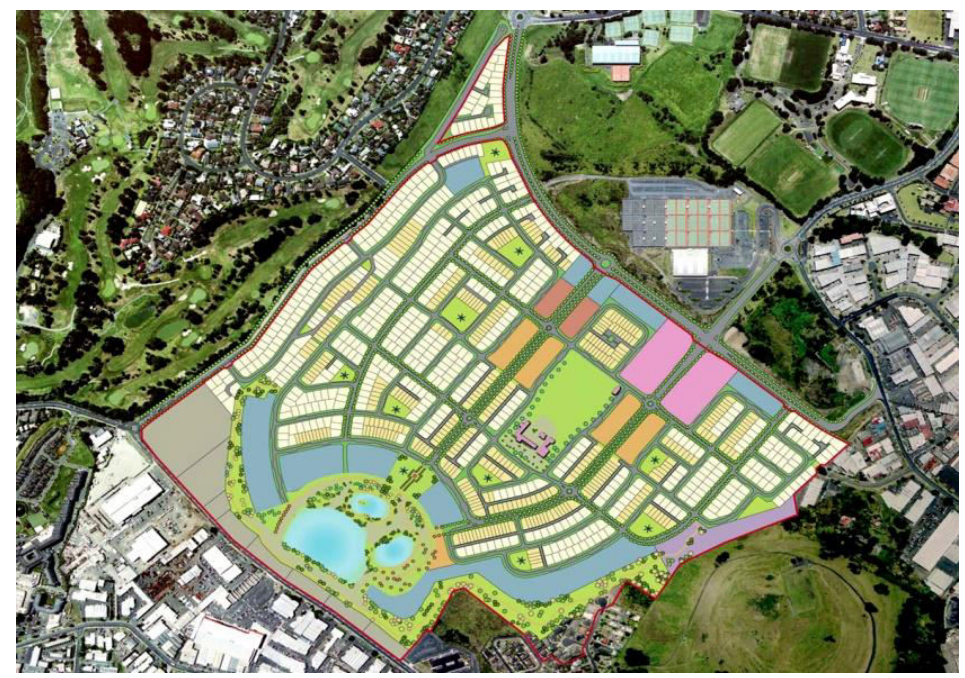

Fig. 6 "Master Plan" of the district of Stonefields belonging to the metropolitan area of Auckland (New Zealand), 2011. (Fletcher Living, 2015) 


\section{FINAL COMMENT}

We must consider that the use of photoplans may pose certain problems in the management of "extensive graphic information" involved in this "new" base plan. Studying in detail the adaptation of the photoplan as a new graphic resource applicable to new ways of presentation, publication and consultation of urban planning work appears to be a field of clear interest to the urban planner. In fact, some "city maps" already exist that explore new mechanisms of planning presentation via the internet. It is not just a question of an adaptation of graphic design to a new platform, but of new technologies already pointing to the possibility of its multiple and combined use. The photoplan thus emerges as a highly specialized and specific tool that allows the technician to consider presentations of the territory and its arrangement that are as innovative as effective.

\section{RE F E R E N C ES}

Baiocchi, V., Lelo, K., Milone, M. V., Mormile M. \& Tanga, E. (2013) Knowing the past for managing the present: a comparison between historical cartography and satellite images for the study of Rome's city centre. Geographia Technica, 8 (1), 17-27.

Collymore, P. (1983) Ralph Erskine. Barcelona, Gustavo Gili.

Fletcher Living, (2015) Stonefields: a new urban village. [Online]. New Zealand, available at: [Accessed 15th March 2016].

Gravagnuolo B. (1998) Historia del urbanismo en Europa: 1750-1960. Madrid, Akal.

Magnago, L. V. (1990) Berlín mañana: Ideas para el corazón de una gran ciudad. Arquitectura del Colegio Oficial de Arquitectos de Madrid, 286-287, 178-195.

Martorell, J. M, Bohigas, O., Mackay, D. \& Puigdomenech, A. (1992) La Villa Olímpica: Barcelona 92: Arquitectura, Parques, Puertos Deportivos = The Olympic Village: Barcelona 92: Architecture, Parks, Leisure Ports. Barcelona, Gustavo Gili.

Pla, M. (1990) "Etapes i evolució" in Quaderns d'Arquitectura i Urbanisme, 205-206, 83-87.

Walker, T. D \& Davis, D.A. (1990) Plan Graphics. Van Nostrand Reinhold, New York.

Vartic, L. (2015) Cartographic visual expression, a means of communication and exploration in architecture and art. Geographia Technica, 10 (1), 90-95. 